\title{
Living Lab - Intelligent Innovation Support for Tourism Development
}

\author{
Irena Šker \\ Juraj Dobrila University of Pula, Faculty of Economics and Tourism "Dr. Mijo \\ Mirković", Pula, Croatia \\ Tamara Floričić \\ Juraj Dobrila University of Pula, Faculty of Economics and Tourism "Dr. Mijo \\ Mirković", Pula, Croatia
}

\section{Abstract}

The aim of the paper is to analyse the justification for and efficiency of the organisation of a Living Lab within the higher education system as an environment for the development of stimulating tourism ideas and entrepreneurship recommendations. The paper proposes the methodology by means of which the set problem area would be addressed and innovative solutions and recommendations reached for tourism entrepreneurship.For the purposes of identification of the concept elements and research methodology which the "Living Lab", as an innovative dynamic laboratory implements, quantitative statistics and qualitative methods of creative thinking Brainstorming and Brainwriting are analysed in the paper. Through the Living Lab model, they contribute to the development of creativity and generate quality and innovative ideas and, in accordance with these, establishment of the most efficient model for problem solving in the tourism environment is proposed. The purpose of the paper is to present an innovative model of consideration and evaluation of problems and potential solutions in tourism entrepreneurship. Summarised considerations represent a scientific contribution to the new theory of problem solving and innovations in tourism entrepreneurship.

Keywords:Living Lab, innovations, tourism and hospitality, entrepreneurship, SME in tourism

JEL classification: 125, O30, Z32

\section{Introduction}

Nowadays, knowledge represents a considerable input for the development of innovations which result in higher degrees of development, more successful economic results and a more competitive position in the modern, challenging and dynamic tourism market.

One of the most important carriers of the growth of productivity and increase in companies' competitiveness, but also of the entire economies, is human capital and its knowledge. As a result, investment in knowledge results in the creation of innovative products and processes, so investment in knowledge is profitable in the long-term as the returns are much higher than the initial costs. Creation of an environment in which human capital occupies first place contributes to the development of innovations and attracts investment and opens possibilities for a sustainable increase in the number of investments which lead towards long-term economic growth and increase in competitiveness. 
The importance of innovations for further economic development is manifested in the most important international and national strategic documents, with a view to creating an encouraging environment. Accordingly, in the international strategic document "Europa 2020" (European Commission, 2010), three priorities are proposed, which complement each other and one of them is smart growth - by developing the economy based on knowledge and innovation. According to the Croatian Ministry of Economics (2014a) at the national level, the operative programme "Competitiveness and cohesion 2014 - 2020", encompasses the priority axis - strengthening of the economy by implementation of research and innovations, while the "Strategy of encouragement of innovations of the Republic of Croatia 2014 - 2020" (Ministry of Economics, 2014b) strives to position development and systematic encouragement of innovations as the principal values of economic success, but also of the society as a whole.

Cooperation in the business, educational, research and other fields, i.e. by combination of different areas, considerably contribute to the development of creativity, new ideas, new processes and, generally, to innovations. By networking people, creativity and the possibility of stimulation of innovations are encouraged. There is, therefore, a mutual connection between the concepts of creativity and innovations, i.e. creativity is the base for innovations which are the result of the applied creativity.

The methods for encouragement of creative thinking are conceived in the way that they assist us in overcoming the "problem of problem solving". There are numerous creative thinking methods which can be applied individually, while some of the methods are directed towards encouragement of group creativity and are thus applied in teams or work groups. The practice showed that group and modified methods are more effective and that the interaction among people gives better results and more encouraging ideas. Creativity is a cooperative phenomenon and the most creative ideas are often the result of different forms of human interaction. Other people, their ideas, proposals, comments, suggestions and even misconceptions, have always served as excellent creative thinking "triggers" (Ranogajec, 2014/2015).

Accordingly, the aim of this paper is to analyse the justifiability and effectiveness of the networking organisation - the Living Lab - in the system of higher education as an environment for the development of stimulating tourism ideas and entrepreneurial proposals and to suggest the methodology by which the set problem would be approached and innovative solutions found, as well as the recommendations for tourism entrepreneurship. In order to develop an innovation, enterprises can collaborate either with academic institutions or other enterprises that would profit from its development (Bozic, 2007). Living Labs belong to the paradigm of open innovations and include an approach directed towards the user, stresses Ranogajec (2014/2015). They provide "physical regions or virtual realities in which stakeholders form publicprivate partnerships (PPP) of companies, public agencies, universities, institutes and users who cooperate with the aim of creating and making of a prototype, validation and testing of new technologies, services and systems within the context of real life" (Leminen, Westerlund \& Nyström, 2012, p. 7). Living labs take advantage of publicprivate partnerships for generating an initial demand and often involve other actors such as small and medium-sized entreprises to lower barriers of entry in complex multistakeholder or highly regulated environments. (Almirall, Lee \& Wareham, 2012).

Ranogajec (2014/2015) elaborates that model which includes partnership between the economy, the public and the governmental bodies, enabling partners to actively participate in the processes of research, development and innovation (Living Lab), achieving an increased affirmation in the world, in which many prestigious universities 
are included. Establishment of the Living Lab for the tourism sector represents a potential for the development of the local tourist companies, the local community and the entire local area. It is very important that the subject of tourism in the Living Lab be directed towards a specific segment, a specific area or a specific form of tourism so that, on this basis, it is possible to recognise the potential target groups in order to avoid general debates which will not generate innovative solutions.

By means of Living Labs "tourist service providers will obtain insight to what tourists actually want" (Lenart, Pucihar \& Malešic, 2014). Not only can such an insight facilitate identification of new markets, but it can also encourage innovations, development and improvement of products (Buhalis \& Amaranggana, 2014) through more frequent interactions among stakeholders in a partnership. Interaction among users (tourists), technology providers and tourist services are the key catalysts of innovations (Hjalager, 2002). In addition, Living Labs have the potential to become the key catalysts of innovations (Schuurman et al. 2013; Lapointe \& Guimont, 2015), encouraging open innovations (Lapointe et al. 2015), thus creating an environment which promotes cooperation among tourism industry stakeholders in order to enable innovations (Najda-Janoszka, 2013). This Living Labs approach has as its aim training for cooperation, which is an important constitutional element of the paradigm of open innovations (Leminen, Westerlund \& Nyström, 2012).

\section{Research design and methodology}

A mixed research approach was used in the paper, i.e. a combination of the qualitative and quantitative approaches, more precisely, an explanatory sequential design, which includes data collection using first the quantitative, then qualitative methods. The data used for the analysis was initially collected using the survey method of the undergraduate and graduate study students, courses of tourism at the Juraj Dobrila University of Pula. All atypical and incomplete values were excluded, whose presence could affect the analysis results. The size of the survey sample was 128.

Following the survey method, for the purpose of testing of the theoretical determinants and research into the possibility of implementation of the concept into the University system, a pilot project testing has been constituted including the methods of team creative thinking, i.e. the brainstorming method, which encompassed the sample of 54 students gathered in 10 teams, and the method of brainwriting, which was made up of a sample of 6 students, were used. The deductive method, the analysis and synthesis method and the statistical methods were used to prove the set hypotheses.

Bearing in mind that each project idea initially comes from a need to solve a specific problem, the need for a detailed and precise analysis of the problem imposes as essential in the Living Lab process. The initial testing phase of a sample of a total of 60 students started with a presentation and mutual acquaintance of students as a test group for the analysis of the feasibility and efficiency of establishment of the Living Lab organisation in the higher education system, with the cultural tourism locations in the south-east part of Istria, in the areas of the Municipality of Ližnjan. A total of six localities of cultural tourism were presented and a common problem of insufficient valorisation of the said cultural localities was set. This is exactly why the problem analysis is a prerequisite for a proper determination of the project goals, thus a prerequisite also for its success.

The second step in the Living Lab process consists of definition of the team, i.e. a group of students and mentors who, working together, can contribute to the research goal. Versatility and diversity of the team members are the preconditions for its creative work, which leads to optimal solutions and to achievement of the main goal, 
with mentors' leadership and expertise. Oriented towards encouragement of creative ideas and innovative solutions in groups, students were organised into 10 teams.

The central Living Lab activity is the research process which is integrated through co-creation, research, experimentation and evaluation of innovative ideas, scenarios, and concepts with the stimulation of the realistic environment. The choice of brainstorming as a method of encouragement for group creativity was due to its exceptional simplicity and practicality in the solution of widespread problems, success in generating ideas and extreme efficiency in being conducted within a team.

Using the brainstorming method, two teams of students elaborated the problem area of insufficient valorisation of each stated cultural locality (1-5), while, using the method of brainwriting, six students, gathered together in a single team, elaborated the problem area of insufficient valorisation of all six stated localities, where every participant had 5 minutes to evaluate each individual case, writing down their ideas for their evaluation. This resulted in 6 participants evaluating 6 cultural localities in a total of 30 minutes.

Following the research and generation of innovative suggestions, the Living Lab process requires their evaluation. It is a process of obtaining raw data, breaking the whole into separate components for individual examination and transformation into information, useful for decision making.

Following the conduct of the quantitative idea generation method at the Living Lab, the qualitative aspect of a specific idea was assessed using 4 idea quality indicators: innovativeness, feasibility, sustainability and potential. In accordance with the methodology (Stevanović, 2016), the assessment was carried out by three experts from the field of entrepreneurship and tourism, from the Faculty of Economics and Tourism "Dr. MijoMirković" from Pula, acquainted with the areas of the analysed cultural localities. In the paper a total of 5 hypotheses were set, directed towards the comparison of innovative idea generation at the LL environment using the brainwriting and brainstorming methods.

- $\mathrm{Hl}$ : the majority of respondents are not familiar with the concept of the Living Lab as a meeting point for creation and testing of new ideas, but most of them participated in the workshops for development of creative entrepreneurial ideas, which can be considered as a part of the Living Lab concept itself.

- H2: given the size of the test sample, i.e. a larger number of respondents gathered in teams for generation of ideas using the brainstorming method, it is assumed that the same method will generate a larger number of ideas than the brainwriting method.

- H3: analysing the qualitative aspect, the generated ideas obtained through the brainstorming method are on average more innovative than the ideas generated using the brainwriting method due to the assumption of a higher quality and a more innovative approach to team work.

- H4: there is an uneven respondents' average grade concerning their own contribution to the generation of innovative ideas and an average grade concerning the innovativeness of the generated ideas using the brainstorming and brainwriting methods.

For the purposes of the qualitative processing of the generated ideas and the research development with a convincing proof of the hypothesis, a deeper comprehension and creation of questions for further research, the method of idea grading according to the following 4 indicators was used: innovativeness, feasibility, sustainability and potential, which was conducted by the experts from the field of entrepreneurship and tourism. 


\section{Results of empirical research and discussion}

Further to the research design and according to its implementation, the results are presented, which confirm or disprove the hypotheses set and which point to the developmental potentials of certain aspects of the innovative Living Lab laboratory.

Assuming that the respondents are not familiar with the meaning of the Living Lab concept as a mostly "new" concept, which is increasingly used in new literatures as the best practice standard in the area of implementation of open innovations in different business fields and, partially, the concept itself also includes workshops of generation of new ideas, the intention was to examine the level of familiarity with the concept itself and to participate in a specific form of idea generating workshops (Living Lab).

\section{Table 1}

Relative Frequencies of Familiarity with the Living Lab Concept and Participation in Workshops for Development of Creative Entrepreneurial Ideas

\begin{tabular}{llll}
\hline & Familiar & Not familiar & Total \\
\hline Frequency $-\mathbf{N}$ & 38 & 88 & 126 \\
$\%$ & 30.2 & 69.8 & 100 \\
\hline & Participation & Non participation & Total \\
Frequency $-\mathbf{N}$ & 28 & 100 & 128 \\
$\%$ & 21.9 & 78.1 & 100 \\
\hline
\end{tabular}

Source: Authors' work

The calculation of the relative frequency shows that the majority of respondents are not familiar with the Living Lab concept, i.e. only $30.2 \%$ of them are familiar with this concept, which is in line with the hypothesis set. However, by calculating the relative frequency of respondents' participation in the workshops for development of creative entrepreneurial ideas, the $\mathrm{H} 1$ set did not prove to be true, i.e. only $28 \%$ of respondents took part in the workshops for development of creative entrepreneurial ideas.

The team efficiency is reflected in the number of generated ideas, i.e. by analyzing the number of generated ideas per team using the brainstorming method. Using arithmetic mean it is noted that the mean value of the generated ideas equals 5 . Team 1 and team 4 obtained the results which are above the arithmetic mean, i.e. they generated 6 ideas each, which leads to the conclusion that the stated teams are the most efficient in comparison with the others.

\section{Table 2}

Number of Generated Ideas Obtained Using the Brainstorming Method per Team

\begin{tabular}{lcccccccccc}
\hline Team & $\mathbf{1}$ & $\mathbf{2}$ & $\mathbf{3}$ & $\mathbf{4}$ & $\mathbf{5}$ & $\mathbf{6}$ & $\mathbf{7}$ & $\mathbf{8}$ & $\mathbf{9}$ & $\mathbf{1 0}$ \\
\hline $\begin{array}{l}\text { No. of generated } \\
\text { ideas }\end{array}$ & 6 & 4 & 5 & 6 & 3 & 5 & 5 & 5 & 4 & 4 \\
$\begin{array}{l}\text { No. of members } \\
\begin{array}{l}\text { Idea per team } \\
\text { member }\end{array}\end{array}$ & 6 & 5 & 7 & 6 & 5 & 5 & 5 & 5 & 5 & 5 \\
\hline
\end{tabular}

Source: Authors' work

The data shows that, according to team work and the number of generated ideas per team, no team presented more ideas in relation to the number of team members. This can be explained by the overlapping of the same ideas which were not expressed, but also by the influence of the collective thinking, where team work is 
aimed towards specific thinking directions where individual creativity does not get affirmed. Furthermore, entities are grouped according to the variable of the number of generated ideas and the results show that one team generated 3 ideas, three teams produced 4 ideas, four teams 5 ideas and two teams produced 6 ideas. Using the method of creative generation of ideas brainstorming, most teams generated 5 ideas, as shown by the arithmetic mean.

Comparing the realized number of ideas with the ideas realized using the brainwriting method, a higher realization frequency is evidenced through the brainwriting method. According to the method used, grouping was carried out and the calculations were made of the relative frequencies: out of the total number of 118 ideas, the brainstorming method produced 47 ideas (39.8\%) and the brainwriting method produced 71 ideas $(60.2 \%)$, which shows that the number of ideas generated using this method is more considerable in relation to the brainstorming method, regardless of the sample size and the $\mathrm{H} 2$ set is, therefore, rejected.

The problem area of team work influence is also researched and argued by numerous authors, stating that experience showed that the best results are obtained when a cognitive ability and richness which other people possess, i.e. personal and social intelligence, are united. They stress that "it is perfectly clear that a group mind can be much more intelligent than the individual; there is much scientific data confirming this. Excellent team work raises the "group intelligence quotient", where one person's best abilities catalyze what is best in others and much better results are obtained from those realized by a single person" (Stevanović, 2016). In his work, he researches and illustrates variables which are most frequently used in the evaluation of the idea capacity for product development, i.e. indicators for assessment.

Following the implementation of the quantitative idea generation in the Living Lab, assessment was carried out of the qualitative aspect of a specific generated idea using 4 idea quality indicators: innovativeness, feasibility, sustainability and potential (Stevanović, 2016). This was carried out by three experts from the field of entrepreneurship and tourism.

In the analysis of the grades of the generated ideas for the indicators and average grade of innovativeness of the generated ideas using the brainstorming method a grade of 2.74 is reached, while the average grade of ideas generated using the brainwriting method equals 3.14, where the grade 1 is unsatisfactory and 5 is excellent. There is no more significant difference between the average grades for innovativeness of the generated ideas using either method; however, the set hypothesis should be rejected as the assumption of a more innovative idea generation in team work using the brainstorming method did not prove to be valid. The reason for this most probably lies in the quantity of the generated ideas, i.e. given that the largest number of ideas were generated using the brainwriting method, the possibility is greater for innovative ideas.

The self-evaluation of own skills can have an overestimated effect, caused by the highest level of needs in Maslow's hierarchy and can therefore present an unreal picture of an individual and a group. 
Table3

Grades of Respondents' Own Skills for Contribution to Innovative Ideas and Experts' Grades for Innovativeness of the Generated Ideas

\begin{tabular}{lllllllll}
\hline & $\mathbf{1}$ & $\mathbf{2}$ & $\mathbf{3}$ & $\mathbf{4}$ & $\mathbf{5}$ & Total - N & $\begin{array}{l}\text { Total } \\
\text { grade }\end{array}$ & Avg. \\
\hline Frequency 1 - N & 0 & 2 & 29 & 25 & 4 & 60 & 212 & 3.53 \\
Frequency 1 - \% & 0 & 3.33 & 48.33 & 41.67 & 6.67 & 100 & & \\
Frequency 2 - N & 51 & 104 & 61 & 83 & 55 & 354 & 1049 & 2.96 \\
Frequency 2 - \% & 14.41 & 29.38 & 17.23 & 23.45 & 15.53 & 100 & & \\
\hline
\end{tabular}

Note: Frequency 1: Grades of respondents' own skills for innovativeness of the generated ideas Frequency 2: Experts' grades for innovativeness of the generated ideas

Source: Authors' work

It should be mentioned, however, that this concerns the expression of respondents' own reflexions and attitudes. This is why the generated attitude towards own skills, which can contribute to the generation of innovative ideas, is verified from a practical aspect. The largest number of respondents graded their skills for contribution to innovative ideas with the grade 3 (mode equals 3), i.e. good, while the average grade of all the respondents was 3.53. Analysing the grades awarded by the experts concerning the innovativeness of generated ideas, it can be concluded that the largest number of generated ideas obtained the grade satisfactory for innovativeness, but that the average grade for innovativeness of generated ideas is 2.96 (grade 3 , good) and that leads to hypothesis $\mathrm{H} 4$ rejection.

Analysing the dominant value, i.e. the mode, the difference is evident, as the highest number of frequencies are of the opinion that personal skills are good for contribution to innovative ideas, but that the grades for the generated ideas of the largest number of frequencies, is sufficient. The respondents believe that their skills for contribution to innovative ideas are slightly higher than it proved in the grading of the innovativeness of ideas which they had generated.

\section{Conclusion}

The justification for and efficiency of the organisation of the Living Lab within the higher education system is evidenced in the networking of students who, by cooperation or team work, using the creative thinking methods, generated a total of 118 ideas for tourism valorisation of specific cultural localities which, using innovativeness indicators, in total were awarded an average grade of good. A large number of generated ideas justifies the efficiency and performance of the organisation of the Living Lab within the higher education system, as an environment for the development of stimulating tourist ideas and entrepreneurial recommendations. Both of the methods used for encouragement of the creative thinking, brainstorming and brainwriting, proved to be exceptionally efficient in the development of new ideas in the Living Lab environment. The brainwriting method generated a larger number of ideas than the brainstorming method, regardless of the larger test sample in the brainstorming method. In the case of a smaller sample, it is assumed that the brainwriting method is more efficient in the generation of a larger number of ideas. There is the possibility of further research into the brainstorming and brainwriting methodologies on the same sample size as well as implementation of Delphi research method supporting new knowledge for innovative solutions. 
Continuously, the research shows that, in view of the analysis of the recorded ideas of a previous respondent, the same ideas appear in the brainwriting method, which, following their generation, have to be selected and rejected. At the same time, the brainwriting method also generates more innovative methods than the brainstorming method, regardless of the innovative approach and discussions of ideas in a team environment, with the research limitation that a larger number of ideas can also generate more innovative ideas.

In comparing the brainstorming and brainwriting methods, we can conclude that, through the brainwriting method, a considerably lower number of respondents contributed to a considerably larger number of generated ideas within half of the time period. However, in the brainstorming method, there is a possibility of further elaboration and discussion of generated ideas, which, using a team approach, can lead to modification of ideas which could be realised through innovative products. By combination of both methods, innovative ideas in entrepreneurship and tourism can be generated and the use of both methods, as a model of generation of ideas in the organisation of the Living Lab, is justified.

Considering two variables, own evaluation for contribution and the expert grading of innovativeness of the generated ideas using both methods, it can be concluded that there is no significant difference; the respondents evaluated themselves correctly but the average grade is not at a higher level.

Finally, the research showed that the majority of the respondents are not generally familiar with the Living Lab concept and that they had never taken part in creative thinking workshops. However, according to the results, the problem is imposing of insufficient networking and cooperation in the development of innovative ideas and insufficient use of the stakeholder potential - students, as a test group in this research. Moreover, this is recognised as a potential for the development of the Living Lab as the incubator of creation of innovative ideas in entrepreneurship and tourism and their testing using innovative technologies in the system of higher education institutions, universities and faculties. The generated results form a base for further research and development of innovative creative techniques, which, by its processing through realistic business situations of tourism entrepreneurship, contribute to the development of the scientific theory and practice.

\section{References}

1. Almirall, E., Lee, M., Wareham, J. (2012), "Mapping Living Labs in the Landscape of Innovation Methodologies", Technology Innovation Management Review, 2 (9), pp. 12 18, available at: http://timreview.ca/article/603 (05 April 2019).

2. Buhalis, D., Amaranggana, A. (2014), "Smart tourism destinations", in the Proceedings of the International Conference on Information and Communication Technologies in Tourism, Dublin, Ireland, Springer, pp. 553-564.

3. European Commission (2010), "Communication from the commission Europe 2020. A strategy for smart, sustainable and inclusive growth", available at: https://ec.europa.eu/eu2020/pdf/COMPLET\%20EN\%20BARROSO\%20\%20\%20007\%20\%20Europe\%202020\%20-\%20EN\%20version.pdf (14 April 2019).

4. Guimont, D., Lapointe, D., Sevigny, A. (2017), "Changing collaborative practices in tourism - a Living Lab case", Canadian Journal of Regional Science, 40 (1), pp. 63-69.

5. Hjalager, A. M. (2002), "Repairing innovation defectiveness in tourism", Tourism Management, Vol. 2, No. 5, pp. 465-474. 
6. Lapointe, D., Guimont, D., Sévigny, A. (2015), "The living lab approach to raise innovation capability among tourism practitioners", Tourism Dimensions, Vol. 2, No. 2, pp. 18-27.

7. Lapointe, D., Guimont, D. (2015), "Open innovation practices adopted by private stakeholders: perspectives for living labs", Info, Vol. 17, No. 4, pp. 67-80.

8. Leminen, S., Westerlund, M., \& Nyström, A. (2012), "Living Labs as open-innovation Networks", Technology Innovation Management Review, pp. 6-11.

9. Lenart, G., Pucihar, A., Malešić, A. (2014), "User-centered design of a web-based platform for the sustainable development of tourism services in a Living Lab context", in Caporarello, L., Di Martino, B., Martinez, M. (Eds.), Smart Organizations and Smart Artifacts: Fostering Interaction Between People, Technologies and Processes, Springer, pp. 251-266.

10. Ministry of Economics (2014), "Operational Programme Competitiveness and Cohesion 2014 - 2020 2014HR16M1OP001 - 1.2", available at: https://www.mingo.hr/public/investicije/OPKK_2014_2020_31316.pdf(14 April 2019).

11. Ministry of Economics (2014), "Strategy of innovation encouragement of the Republic of Croatia 2014-2020" available at: https://narodne-novine.nn.hr/clanci/sluzbeni/dodatni/434155.pdf(14 April 2019).

12. Najda-Janoszka, M. (2013), "Innovative activity of small tourist enterprises - cooperation with local institutional partners", Journal of Entrepreneurship, Management and Innovation, Vol. 9, No. 1, pp. 17-32.

13. Ranogajec, V. (2014/2015), "Brainstorming, brainwriting and Delphi method", Introduction in science research paper, Doctoral study, Faculty of Mechanical Engineering and Naval Architecture, University of Zagreb

14. Schuurman, D., De Marez, L., Ballon, P. (2013), "Open innovation processes in Living Lab innovation systems: insights from the LeYLab", Technology Innovation Management Review Novembe, Vol. 3, No. 11, pp. 28-36.

15. Stevanović, M., Marjanović, D., Štorga, M. (2016), "Idea assessment and selection in product innovation - the empirical research results", Technical gazette, 23 (6), pp. 17071716, available at https://hrcak.srce.hr/169359(02 April 2019). 


\section{About the authors}

Irena Šker, MSc is a senior expert in project Atlas, Interreg V-A Italy - Croatia 2014 2020 CBC Programme, Standard+, at Juraj Dobrila University of Pula, Croatia, Faculty of Economics and Tourism "Dr.MijoMirković". She received MSc Specialisation in Organisation and Management at the Faculty of Economics in Osijek with the master thesis "Management style research in Agrokor company ". She was also an assistant (seminars and exercises) at the Business College with public rights "Manero" in Višnjan. Her main research interests are innovations in tourism, management and entrepreneurship. The author can be contacted at irena.sker@unipu.hr.

Tamara Floričić, PhD is an assistant professor of Tourism at Juraj Dobrila University of Pula, Croatia, Faculty of Economics and Tourism "Dr.MijoMirković". She lectures in the courses related to tourism and hospitality. She is the author of many research papers focused on hospitality, innovations in organisation and marketing in the hospitality business, topics which she also explores in co-authorship books. She is an active reviewer and member of the scientific journal editorial board. She was included as a researcher in the scientific project ZP UNIRI 7/16.: "Innovative Accommodation Structures in the Context of Increased Competitiveness of Tourist Destinations" and she is project manager of University partner project Interreg - Italy Croatia 2014 - 2020 Interreg V-A- Italy Croatia CBC Programme, Standard+ Atlas. The author can be contacted at tfloricic@unipu.hr. 